\title{
Assessment of the Role of Total Antioxidant Capacity and Troponin I as Possible Predictors for Phosphides -Induced Cardiotoxicity
}

\author{
Marwa Abdel Wahab, Sawsan Shalaby, Eglal El Awady, Rania Hussien and ${ }^{1}$ Waleed Salah Eldin ${ }^{2}$
}

${ }^{1}$ Department of Forensic Medicine and Clinical Toxicology

${ }^{2}$ Department of Community.

Faculty of Medicine-Ain Shams University, Cairo, Egypt.

All rights reserved.

\begin{abstract}
Background: Metal phosphides are type of rodenticides that are extremely lethal with low safety and high mortality rates. They are commonly used as a powerful suicidal tool in Egypt and developing countries due to its low price and easy availability. Heart is a significant target organ of acute metal phosphides toxicity, causing myocardial damage and myocarditis. Aim: The study aimed to evaluate usefulness of total antioxidant capacity (TAC) and troponin I as predictive biomarkers for phosphides induced oxidative stress and cardiotoxicity among patients admitted to the Poison Control Center Ain Shams University Hospitals (PCC-ASUH). Methods and results: A prospective study included patients of both sexes presented to the PCC-ASUH with acute metal phosphides poisoning during six months period from July to December 2017. The demographic, intoxication and clinical data were collected for every patient. On admission investigations included electrocardiogram (ECG) in addition to TAC and troponin I levels. Outcome was also recorded. This study was conducted on 188 patients of both sexes with acute metal phosphides poisoning. The patients were classified according to the Poisoning Severity Score (PSS) into three groups; mild, moderate and severe. TAC value was significantly decreased in patients who developed cardiovascular manifestations and ECG abnormalities. Serum troponin I value was significantly higher in patients who developed cardiovascular manifestations and ECG abnormalities. Conclusion: The current study concluded that TAC and troponin I levels could be useful in predicting development of oxidative damage, cardiotoxicity and mortality after acute metal phosphides poisoning. Recommendations: The present study recommended the use of TAC and troponin I as useful markers for prediction of cardiotoxicity and mortality in patients with acute metal phosphides poisoning.
\end{abstract}

Key words poisoning, phosphides, cardiotoxicity, oxidative stress

\section{Introduction}

$\mathrm{R}$ odenticides toxicity has been a public health problem worldwide, as about 250000 to 370000 individuals die each year due to exposure. It is the second common cause of suicidal attempts worldwide after organophosphates as it is responsible for about onethird of these attempts (Hashemi-Domeneh et al., 2016; Manouchehri et al., 2019).
Metal phosphides are type of rodenticides that are extremely lethal with low safety and high mortality rates as high as 70-100\% (Mehrpour et al., 2012; Etemadi-Aleagha et al., 2015). They are commonly used as a powerful suicidal tool in Egypt and developing countries due to their lower price, widespread use as a strong rodenticide and easy availability (Sagah et al., 2015; Badawi et al., 2018). 
The exact mechanism of acute phosphides toxicity has not been well defined despite the high mortality rates that are reported following significant exposures to aluminium or zinc phosphides and its treatment is still supportive including rapid decontamination and institution of resuscitative measures (Goharbari et al., 2018).

Evidence of reactive oxygen species-induced toxicity owing to metal phosphides has been observed in insects and rats. A similar mechanism could also play a role in humans and contribute to the missing link in the pathogenesis of their toxicity but there is a limitation of data measuring the total antioxidant capacity in patients with aluminum phosphide (ALP) toxicity. Many studies have been carried out to calculate oxidative stress markers in acute aluminium phosphide poisoning while no studies have been done on acute zinc phosphide $(\mathrm{ZnP})$ poisoning (Kariman et al., 2012 and Sagah et al, 2015).

Heart is a significant target organ of metal phosphides toxicity as they affect the cardiac and vascular tissues in the form of direct myocardial tissue damage, hypoperfusion, myocarditis, pericarditis, arrhythmias and elevated cardiac biomarkers (Doğan et al., 2014; Elabbassi et al., 2014; Mohan et al., 2016; Yogendranathan et al., 2017).

Significant elevation of troponin is an indicative of injury to the myocardium. A small elevation of troponin I (but a normal CK-MB level) may indicate a microscopic zone of myocardial necrosis (microinfarction), truly elevated troponin I levels have also been documented in tachyarrhythmias and myocarditis (Xue et al., 2014).

Most of metal phosphides intoxicated patients died during the first 24 hours following exposure from cardiotoxicity (Jain, 2018; Sinha, 2018).

\section{Aim of Study}

This study aims to:

1. Assess frequency of cardiovascular manifestations and ECG changes produced by acute phosphides toxicity in patients admitted to Poison Control Center Ain Shams University Hospitals (PCC-AUH).

2. Evaluate the usefulness of TAC and troponin I as predictive biomarkers for phosphides induced oxidative stress and cardiotoxicity for intensive monitoring and early management to decrease mortality rate and improve outcome.

\section{Patients and Methods}

Study design: A prospective cross sectional study was conducted on acute phosphides intoxicated patients admitted to the PCC-ASUH during six months period from July 2017 to December 2017.

Exclusion criteria: patients who received prehospital treatment, patients with co-ingestion of cardiotoxic drugs or toxins, pregnant females and patients who had history of cardiac, renal, hepatic, respiratory, neurological, endocrinal or autoimmune disease.
Ethical Considerations: An official permission was taken from the general director of the PCC-ASUH. The approval of the Local Research Ethics Committee was obtained. An informed valid consent was taken from patients or their legal guardians. All personal data were kept anonymous to ensure confidentiality of records.

Data collection: The sociodemographic data and intoxication data were collected. Vital data include pulse, blood pressure, respiratory rate and body temperature were checked. Normal values were stated according to Rees et al. (2017). Cardiovascular (CVS) examination included presence of abnormal or impalpable pulse, signs of shock or cardiac arrest. Shock was diagnosed if systolic blood pressure $<90 \mathrm{mmHg}$, weak pulse and evidence of end organ dysfunction such as cool or mottled skin, oliguria or hepatic insufficiency or altered mental status (Dunn et al., 2018).Outcome was also recorded.

Blood samples: A blood sample was collected for all patients on admission then it was transferred to a clean dry centrifuge tube and left for few hours to clot. After complete clotting, it was centrifuged for 10 minutes at $5000 \mathrm{rpm}$. Serum was separated, stored in the freezer minus $80^{\circ} \mathrm{C}$ and used later after collection of all samples.

Measurement of plasma total antioxidant capacity (TAC): The principle of the ABTS (2,2'-azino-bis(3ethylbenz-thiazoline-6-sulfonic acid) method for determining the TAC is as follow. $\mathrm{ABTS}^{+}$is oxidized to green ABTS by appropriate oxidant, which can be inhibited if antioxidants exist. The TAC of the sample can be determined and calculated by measuring the absorbance of $\mathrm{ABTS}^{+}$at $414 \mathrm{~nm}$ or $734 \mathrm{~nm}$ (Allard, 1998).

Measurement of troponin I was done by using Enzyme Immunoassay test kit for the Quantitative determination of cardiac troponin-I in human serum.

Electrocardiogram (ECG): ECG analysis included the rate, rhythm, ST/T abnormalities, conduction defects and measurement of PR and QT intervals. The QT interval was corrected (QTc) according to the formula of Bazett, in which the QT interval is adjusted for heart rate by dividing it by the square root of the R-R interval. QTc $=\mathrm{QT} / \sqrt{\mathrm{RR}}$.

Statistical analysis: Data were collected, checked, revised, coded and tabulated using SPSS Version 20. I. Descriptive statistics: 1.Data were tested for normality with Kolmogorov-Smirnov test and expressed as mean (standard deviation) for parametric numerical data or median (interquartile range) for non parametric numerical data. 2. Frequency and percentage of non-numerical data.

II. Analytical statistics: Mann Whitney Test (U test) was used to assess the statistical significance of the difference of a non parametric variable between two study groups, Kruskal-Wallis test was used to assess the statistical significance of a non parametric variable between more than two study groups, Dunn-Bonferroni Post Hoc test was used after a significant Kruskal-Wallis test for comparisons of all possible pairs of study groups. 
Correlation analysis (using spearman's method) was used to assess the strength of association between two quantitative variables. The correlation coefficient denoted symbolically " $r$ " defines the strength and direction of the linear relationship between two variables. $P$ value: level of significance: $P>0.05$ : Non significant. $\mathrm{P}<0.05$ : Significant. $\mathrm{P}<0.01$ : Highly significant. One Way ANOVA test was used to declare the significant difference between groups at $\mathrm{p}<0.05$ for the quantitative variables which are normally distributed. The results of statistical analysis were then represented in tables for interpretation and discussion.

\section{Results}

A total of 188 patients with acute phosphides intoxication were enrolled in the study. Patients were classified according to the poisoning severity score (PSS) (Persson et al., 1998) into three groups: group I (mild group), group II (moderate group) and group III (severe group). The mean age of studied patients was $24.67 \pm 11.29$ year with female predominance $(63.3 \%)$, near half were students $(46.3 \%)$, mostly from Cairo $(76.1 \%)$ (table 1). Most of patients were intoxicated with zinc phosphide $(92.6 \%)$ mostly through ingestion $(97.9 \%)$. Suicide was the most common manner of poisoning among studied patients $(87.2 \%)$. As regards the ingested amount of phosphides, $29.3 \%$ of studied patients ingested unknown amount, most of zinc phosphide poisoned patients ingested 1 sachet $(40.2 \%)$ and about one third of aluminum phosphide poisoned patients (21.4\%) ingested 1 tablet (table 2). The median delay time was 3(2-5) hours in all studied groups. There was a significant decrease of the delay time in patients of group I when compared with group II and III by using post of Kruskal Wallis test.

Regarding vital data, there was a highly statistical significant difference between groups by using one way ANOVA test (table 3). On applying the post hoc Tukey HSD test, heart rate was significantly increased in group II \& III when compared with the group I while there was non significant difference between group II and III. Systolic and diastolic blood pressure were significantly decreased in group III when compared with group I and II while there was non significant difference between group I and II. Respiratory rate was statistically increased in group III when compared with group I and II, while there was a non significant difference between group I and II. Body temperature was statistically decreased in group III when compared with group I and II, while there was a non significant difference between group I and II (table 3). Concerning the cardiovascular manifestations, palpitation occurred in $6.9 \%$ of studied patients, $4.3 \%$ complained of chest pain, 11 cases $(5.9 \%)$ had shock, 8 cases $(4.3 \%)$ developed cardiac arrest (table 4).

ECG findings among studied patients revealed sinus tachycardia in $28.7 \%$ of the patients, prolonged QT interval in more than one third of patients $(38.3 \%)$, wide QRS complex in $20.2 \%$, elevated ST segment in 3.2\%, depressed ST segment in $2.7 \%$, inverted $\mathrm{T}$ wave in $10.6 \%$ and tall $\mathrm{T}$ wave $3.2 \%$.About $2 \%$ of patients had nodal rhythm, $1.14 \%$ had PVC, $0.56 \%$ had VT and VF was observed in $1.6 \%$ of studied patients (table 5). There was a highly significant difference between the studied groups by using ANOVA test as regards PR interval and QTc intervals while there was non significant difference as regards QRS complex. On applying post hoc Tuckey test, group II showed statistically significant increase of PR interval in comparison with group I and III while there was non significant difference between group I and III. Concerning QTc interval, it was increased in group II when compared with group I and was longer in group III than in group I and II (table 6).

Table (7) shows the values of TAC and troponin I for the studied groups. Statistical analysis by using Kruskal Wallis test revealed that there was a highly significant difference between the studied groups as regards TAC and troponin I. On applying DunnBonferroni Post-hoc of Kruskal Wallis test, group III showed statistically significant decrease in values of TAC in comparison with group I and II while there was non significant difference between group I and II. Regarding troponin I it was significantly increased in group III in comparison with group I and II while there was non significant difference between group I and II.

On performing spearman correlation coefficient analysis, significant positive correlations were detected between TAC and blood pressure (systolic and diastolic), and significant negative correlations with pulse and respiratory rate, while troponin I showed a highly significant positive correlations with pulse and respiratory rate, and significant negative correlation with blood pressure (systolic and diastolic) (table 8).The median value of total antioxidant capacity was lower in patients who developed cardiovascular manifestations, while the median value of troponin I was higher in patients who developed cardiovascular manifestations. There was a highly statistically significant difference between the studied groups as regards the pulse by using Kruskal Wallis test. On appling Dunn bonferroni post hoc test, TAC value was lower in patients who had either tachycardia or bradycardia when compared with those who had a normal pulse (table 9).

Table (10) shows relation of ECG abnormalities to values of TAC and troponin I in studied patients by using Mann-Whitney test. The median value of TAC was lower in patients who developed ECG abnormalities when compared with patients who had normal ECG findings. As regards serum troponin I value, it was higher in patients who developed ECG changes when compared with patients who had normal ECG findings.

As regards outcome of studied patients, majority of patients (92\%) recovered and discharged without any complications, 8 cases (4.3\%) developed respiratory failure, 11 cases $(5.9 \%)$ developed myocardial ischemia and 5 cases $(2.7 \%)$ died (table 11$)$. 
Table (12) shows the best cut off value, sensitivity and specificity of TAC and troponin I for prediction of mortality in patients with acute phosphides. The area under the curve for TAC was 0.765 (0.697to0.824), the best cut off point was $\leq 0.07 \mathrm{mM} / \mathrm{L}$, with sensitivity of $100 \%$ and specificity of $63.54 \%$. The area under the curve for troponin was 0.97(0.94 to 0.99), the best cut off point was $\geq 2.95 \mathrm{ng} / \mathrm{ml}$, with sensitivity of $100 \%$ and specificity of $90.06 \%$.

Table (1): Frequency of sociodemographic data for the studied patients

\begin{tabular}{|c|c|c|c|}
\hline \multicolumn{2}{|c|}{ Sociodemographic data } & Number $(N=188)$ & Percentage $(\%)$ \\
\hline Age (Years) & Mean \pm SD & \multicolumn{2}{|c|}{$24.67 \pm 11.29$} \\
\hline \multirow{2}{*}{ Gender } & Male & 69 & 36.7 \\
\hline & Female & 119 & 63.3 \\
\hline \multirow{5}{*}{ Occupation } & Student & 87 & 46.3 \\
\hline & Non-working & 59 & 31.4 \\
\hline & House wife & 26 & 13.8 \\
\hline & skilled Worker & 10 & 5.3 \\
\hline & specialist & 6 & 3.1 \\
\hline \multirow{4}{*}{ Residence } & Cairo & 143 & 76.1 \\
\hline & Delta & 29 & 15.5 \\
\hline & Upper Egypt & 15 & 7.9 \\
\hline & Suez canal & 1 & 0.5 \\
\hline
\end{tabular}

SD: standard deviation

Table (2): Distribution of the studied patients according to the intoxication data

\begin{tabular}{|c|c|c|c|c|}
\hline \multicolumn{3}{|c|}{ Intoxication data } & Number (188) & Percentage $(\%)$ \\
\hline \multirow{2}{*}{ Type of phosphide } & \multicolumn{2}{|l|}{ Zinc phosphide } & 174 & 92.6 \\
\hline & \multicolumn{2}{|c|}{ Aluminum phosphide } & 14 & 7.4 \\
\hline \multirow{2}{*}{ Route of poisoning } & \multicolumn{2}{|l|}{ Ingestion } & 184 & 97.9 \\
\hline & \multicolumn{2}{|l|}{ Inhalation } & 4 & 2.1 \\
\hline \multirow{3}{*}{ Mode of exposure } & \multicolumn{2}{|l|}{ Suicidal } & 164 & 87.2 \\
\hline & \multicolumn{2}{|l|}{ Accidental } & 21 & 11.2 \\
\hline & \multicolumn{2}{|l|}{ Occupational } & 3 & 1.6 \\
\hline \multirow{10}{*}{ Amount } & \multicolumn{2}{|l|}{ Unknown } & 55 & 29.3 \\
\hline & \multirow{6}{*}{$\begin{array}{c}\text { Zinc phosphide } \\
\text { (sachet } 2-\mathbf{3} \text { grams) }\end{array}$} & 1 & 70 & 40.2 \\
\hline & & 0.5 & 35 & 20.1 \\
\hline & & 1.5 & 8 & 4.6 \\
\hline & & 2 & 7 & 4 \\
\hline & & 3 & 2 & 1.15 \\
\hline & & 4 & 2 & 1.15 \\
\hline & \multirow{3}{*}{$\begin{array}{l}\text { Aluminum phosphide } \\
\text { (tablet } 3 \text { grams) }\end{array}$} & 0.25 & 3 & 21.4 \\
\hline & & 0.5 & 3 & 21.4 \\
\hline & & 1 & 3 & 21.4 \\
\hline
\end{tabular}

Table (3): One way ANOVA test for comparison of vital data in the studied groups

\begin{tabular}{|c|c|c|c|c|}
\hline \multirow{2}{*}{ Vital data } & $\begin{array}{c}\text { Group I } \\
(\mathbf{N = 1 0 0 )}\end{array}$ & $\begin{array}{c}\text { Group II } \\
(\mathbf{N}=73)\end{array}$ & $\begin{array}{c}\text { Group III } \\
(\mathbf{N = 1 5})\end{array}$ & One way ANOVA test \\
\cline { 2 - 5 } & Mean \pm SD & Mean \pm SD & Mean \pm SD & P-value \\
\hline Heart rate (beat/minute) & $87.19 \pm 15.93$ & $99.34 \pm 24.08$ & $99.93 \pm 36.51$ & $<0.001 * *(\mathbf{A 1})$ \\
\hline Systolic blood pressure (mmHg) & $111.4 \pm 11.53$ & $109.73 \pm 14.04$ & $87.67 \pm 14.25$ & $<0.001 * *(\mathbf{A 2})$ \\
\hline Diastolic blood pressure (mmHg) & $71.3 \pm 7.87$ & $69.04 \pm 10.43$ & $56 \pm 11.83$ & $<0.001 * *(\mathbf{A 2})$ \\
\hline Respiratory rate (breath/minute) & $23.25 \pm 3.12$ & $23.53 \pm 3.94$ & $27.27 \pm 5.04$ & $<0.001 * *(\mathbf{A 2})$ \\
\hline Temperature $\left.\mathbf{~}^{\mathbf{0}} \mathbf{C}\right)$ & $37.03 \pm 0.15$ & $37 \pm 0$ & $36.83 \pm 0.41$ & $<0.001 * *(\mathbf{A 2})$ \\
\hline
\end{tabular}

N: Number

SD: Standard Deviation

Post-hoc Tukey HSD test is significant between: ${ }^{(A 1)}$ group I versus group II.
${ }^{(A 2)}$ group III versus (groups I and II) 
Table (4): Frequency of cardiovascular manifestations among the studied patients

\begin{tabular}{|c|c|c|}
\hline & Number (188) & Percentage (\%) \\
\hline Palpitation & 13 & 6.9 \\
\hline Chest pain & 8 & 4.3 \\
\hline Shock & 11 & 5.9 \\
\hline Cardiac arrest & 8 & 4.3 \\
\hline
\end{tabular}

Table (5): Frequency of ECG abnormalities among the studied patients

\begin{tabular}{|c|c|c|}
\hline ECG findings & Number & Percentage (\%) \\
\hline Sinus tachycardia & 54 & 28.7 \\
\hline Sinus Bradycardia & 10 & 5.3 \\
\hline Prolonged QT interval & 72 & 38.3 \\
\hline Wide QRS complex & 38 & 20.2 \\
\hline ST segment and T wave changes & & \\
Elevated ST segment & 6 & 3.2 \\
Depressed ST segment & 5 & 2.7 \\
Inverted T wave & 20 & 10.6 \\
Tall T wave & 6 & 3.2 \\
\hline Nodal rhythm & 4 & 2.1 \\
\hline Premature ventricular tachycardia(PVC) & 2 & 1.14 \\
\hline Ventricular tachycardia(VT) & 1 & 0.56 \\
\hline Ventricular fibrillation(VF) & $\mathbf{3}$ & $\mathbf{1 . 6}$ \\
\hline
\end{tabular}

Table (6): One way ANOVA test for comparison of ECG intervals in the studied groups

\begin{tabular}{|c|c|c|c|c|}
\hline \multirow{2}{*}{ ECG intervals } & $\begin{array}{l}\text { Group I } \\
(\mathbf{N}=100)\end{array}$ & $\begin{array}{c}\text { Group II } \\
(\mathrm{N}=73)\end{array}$ & $\begin{array}{c}\text { Group III } \\
(\mathbf{N}=15)\end{array}$ & $\begin{array}{c}\text { One way } \\
\text { ANOVA test }\end{array}$ \\
\hline & Mean \pm SD & Mean \pm SD & Mean \pm SD & P-value \\
\hline PR interval (millisecond) & $145.81 \pm 26.33$ & $158.33 \pm 27.61$ & $131.73 \pm 19.72$ & $<0.001 * *(\mathbf{A 1})$ \\
\hline QRS complex(millisecond) & $105.62 \pm 21.05$ & $112.33 \pm 24.8$ & $111.8 \pm 25.78$ & 0.145 \\
\hline QTe interval (millisecond) & $407.52 \pm 56.33$ & $516.84 \pm 66.98$ & $473.6 \pm 85.98$ & $<0.001 * *(\mathbf{A 2})$ \\
\hline
\end{tabular}

N: Number SD: Standard Deviation $\quad P$ value $>0.05$ : non-significant $P$ value $<0.001$ : highly significant $* *$ Post-hoc Tukey HSD test is significant between: ${ }^{(A 1)}$ group II versus (groups I and III) ${ }^{(A 2)}$ the three groups.

Table (7): Kruskal Wallis test for comparison of TAC and Troponin I in the studied groups

\begin{tabular}{|c|c|c|c|c|}
\hline \multirow[t]{2}{*}{ Parameters } & $\begin{array}{l}\text { Group I } \\
(\mathbf{N}=100)\end{array}$ & $\begin{array}{c}\text { Group II } \\
(\mathrm{N}=73)\end{array}$ & $\begin{array}{c}\text { Group III } \\
(N=15)\end{array}$ & Kruskal Wallis Test \\
\hline & Median (IQR) & Median (IQR) & Median (IQR) & P-value \\
\hline TAC $(\mu \mathrm{M} / \mathrm{l})$ & $0.18(0.06-0.28)$ & $0.09(0.04-0.19)$ & $0.03(0.01-0.06)$ & $<0.001 * *(\mathrm{k} 1)$ \\
\hline Troponin I (ng/ml) & $1.02(0.8-1.5)$ & $1.4(0.8-2)$ & $3.5(1.6-5)$ & $<0.001 * *(\mathrm{k} 1)$ \\
\hline
\end{tabular}

$N$ : Number IQR (interquartile range) Pvalue >0.05: non-significant P value <0.001: highly significant **

(K) Kruskal Wallis Post-hoc of Kruskal Wallis test is significant between: (KI) group III Vs. (groups I and II).

Table (8): Spearman correlation analysis between TAC and troponin I values in relation to the vital data of the studied patients

\begin{tabular}{|c|c|c|c|c|}
\hline \multirow{2}{*}{} & \multicolumn{2}{|c|}{ Total antioxidant capacity } & \multicolumn{2}{c|}{ Troponin I } \\
\cline { 2 - 5 } & Spearman's rho & P-Value & Spearman's rho & P-Value \\
\hline Pulse (beat/minute) & -0.203 & $<0.001^{* *}$ & 0.219 & $<0.001^{* *}$ \\
\hline Systolic blood pressure (mmHg) & 0.266 & $<0.001^{* *}$ & -0.243 & $<0.001^{* *}$ \\
\hline Diastolic blood pressure (mmHg) & 0.290 & $<0.001^{* *}$ & -0.308 & $<0.001^{* *}$ \\
\hline Respiratory rate (breath/minute) & -0.175 & $<0.05^{*}$ & 0.084 & 0.250 \\
\hline Temperature $\left.\mathbf{(}^{\mathbf{0}} \mathbf{C}\right)$ & 0.023 & 0.754 & -0.114 & 0.120 \\
\hline
\end{tabular}

$r=1$ means a perfect positive correlation

$P$ value >0.05: non-significant $r=-1$ means a perfect negative correlation

$P$ value $<0.05:$ significant $* \quad P$ value $<0.001:$ highly significant $* *$ 
Table (9): Mann-Whitney test for relation of cardiovascular manifestations to values of TAC and troponin I

\begin{tabular}{|c|c|c|c|c|c|}
\hline \multirow{2}{*}{\multicolumn{2}{|c|}{ Cardiovascular manifestations }} & $\begin{array}{l}\text { Total antioxidant } \\
\text { capacity (TAC) }\end{array}$ & \multirow[b]{2}{*}{ P-Value } & Troponin I & \multirow{2}{*}{ P-Value } \\
\hline & & Median (IQR) & & Median (IQR) & \\
\hline \multirow{2}{*}{ Chest pain } & Absent & $0.15(0.05-0.25)$ & \multirow{2}{*}{$0.001 * *$} & $1.10(0.8-1.9)$ & \multirow{2}{*}{$0.001^{* *}$} \\
\hline & Present & $0.03(0.0075-0.045)$ & & $3.40(2.45-5.25)$ & \\
\hline \multirow{2}{*}{ Palpitation } & Absent & $0.15(0.05-0.25)$ & \multirow{2}{*}{$0.001 * *$} & $1.10(0.8-1.7)$ & \multirow{2}{*}{$0.001 * *$} \\
\hline & Present & $0.04(0.01-0.06)$ & & $2.90(2-3.8)$ & \\
\hline \multirow{2}{*}{ Hypotension } & Absent & $0.17(0.07-0.25)$ & \multirow[t]{2}{*}{$0.018^{*}$} & $1.00(0.7-1.6)$ & \multirow{2}{*}{$0.001^{* *}$} \\
\hline & Present & $0.08(0.03-0.25)$ & & $1.40(0.92-2)$ & \\
\hline \multirow{3}{*}{ Heart rate } & Normal & $0.18(0.07-0.26)$ & \multirow{3}{*}{$<0.001^{(\mathbf{K})(\mathbf{a}) * *}$} & $1.00(0.8-1.6)$ & \multirow{3}{*}{$0.003^{(\mathbf{K})(\mathbf{a})^{*}}$} \\
\hline & Tachycardia & $0.06(0.02-0.17)$ & & $1.75(1-2.7)$ & \\
\hline & Bradycardia & $0.06(0.03-0.07)$ & & $2.00(1-4.7)$ & \\
\hline \multirow{2}{*}{ Shock } & Absent & $0.15(0.05-0.25)$ & \multirow{2}{*}{$<0.001 * *$} & $1.10(0.8-1.7)$ & \multirow{2}{*}{$<0.001 * *$} \\
\hline & Present & $0.02(0.006-0.06)$ & & $3.80(3-5.5)$ & \\
\hline \multirow{2}{*}{ Cardiac arrest } & Absent & $0.15(0.05-0.25)$ & \multirow{2}{*}{$<0.001 * *$} & $1.10(0.8-1.85)$ & \multirow{2}{*}{$<0.001 * *$} \\
\hline & Present & $0.03(0.006-0.055)$ & & $4.85(3.25-5.75)$ & \\
\hline
\end{tabular}

$P$ value $>0.05$ : non-significant $P$ value $<0.05$ : significant $*$

${ }^{(K)}$ Kruskal Wallis test ${ }^{(a)}$ Normal versus Tachycardia, Normal versus Bradycardia, using Dunn bonferroni post hoc test

Table (10): Mann-Whitney test for relation of ECG abnormalities to values of TAC and troponin I in studied patients

\begin{tabular}{|c|c|c|c|c|c|}
\hline \multirow{2}{*}{\multicolumn{2}{|c|}{ ECG abnormalities }} & Total antioxidant capacity & \multirow{2}{*}{ P-Value } & Troponin I & \multirow{2}{*}{ P-Value } \\
\hline & & Median (IQR) & & Median (IQR) & \\
\hline \multirow{2}{*}{ Rhythm } & Regular & $0.15(0.05-0.25)$ & \multirow{2}{*}{$0.001 * *$} & $1.13(0.8-1.9)$ & \multirow{2}{*}{$0.001 * *$} \\
\hline & Irregular & $0.01(0.006-0.05)$ & & $3.65(3-5)$ & \\
\hline \multirow{2}{*}{ QRS complex } & Normal & $0.14(0.045-0.25)$ & \multirow{2}{*}{0.418} & $1.05(0.8-1.75)$ & \multirow{2}{*}{$0.014 * *$} \\
\hline & Wide & $0.10(0.04-0.23)$ & & $1.40(1-3)$ & \\
\hline \multirow{2}{*}{ QTc interval } & Normal & $0.17(0.055-0.255)$ & \multirow[t]{2}{*}{$0.012^{*}$} & $1.04(0.8-1.6)$ & \multirow{2}{*}{$0.018 * *$} \\
\hline & Prolonged & $0.08(0.03-0.19)$ & & $1.50(0.9-2.5)$ & \\
\hline \multirow{2}{*}{ ST segment } & Normal & $0.15(0.05-0.25)$ & \multirow{2}{*}{$<0.001 * *$} & $1.10(0.8-1.9)$ & \multirow{2}{*}{$<0.001^{* *}$} \\
\hline & Abnormal & $0.03(0.006-0.06)$ & & $3.50(1.6-5)$ & \\
\hline \multirow{2}{*}{ T wave } & Normal & $0.15(0.05-0.25)$ & \multirow{2}{*}{$0.047 *$} & $1.20(0.8-1.9)$ & \multirow{2}{*}{0.325} \\
\hline & Abnormal & $0.06(0.03-0.17)$ & & $1.30(0.8-2.9)$ & \\
\hline
\end{tabular}

IQR (interquartile range); $P$ value $>0.05:$ non-significant $P$ value $<0.05:$ significant $* P$ value $<0.001$ : highly significant $* *$

Table (11): Distribution of outcome among the studied patients

\begin{tabular}{|c|c|c|}
\hline Outcome & Number (188) & Percentage (\%) \\
\hline Recovery & 173 & 92 \\
\hline Respiratory failure & 8 & 4.3 \\
\hline Myocardial ischemia & 11 & 5.9 \\
\hline Death & 5 & 2.7 \\
\hline
\end{tabular}

Table (12): The best cut off value, sensitivity and specificity of TAC and troponin I for prediction of mortality in patients with acute phosphides poisoning

\begin{tabular}{|c|c|c|c|c|c|c|c|c|}
\hline Parameter & $\begin{array}{c}\text { Area under the ROC } \\
\text { curve (95\% CI) }\end{array}$ & $\begin{array}{c}\text { Cutoff } \\
\text { value }\end{array}$ & $\begin{array}{c}\text { Sensitivity } \\
(\mathbf{\%})\end{array}$ & $\begin{array}{c}\text { Specificity } \\
(\mathbf{\%})\end{array}$ & PPV & NPV & $\begin{array}{c}\text { Accuracy } \\
(\boldsymbol{\%})\end{array}$ & p value \\
\hline TAC (mmol/L) & $0.765(0.697$ to0.824) & $\leq 0.07$ & 100 & 63.54 & 7.0 & 100.0 & 64.5 & $0.001^{* *}$ \\
\hline $\begin{array}{c}\text { Troponin I } \\
(\mathbf{n g} / \mathbf{m l})\end{array}$ & $0.97(0.94$ to0.99) & $\geq 2.95$ & 100 & 90.06 & 21.7 & 100.0 & 90.3 & $0.001^{* *}$ \\
\hline
\end{tabular}

PPV: Positive predictive value NPV: Negative predictive value P value $<0.001$ : highly significant $* *$

CI: Confidence interval 


\section{Discussion}

Acute phosphides poisoning result in significant morbidity and mortality. The most common cause of early death is cardiac dysrhythmia while late death occurred due to persistent shock or hepatic failure (Anand et al., 2011; Neki et al., 2017). This study focused on assessing the role of troponin I and TAC as predictive biomarkers for phosphides induced oxidative stress and cardiotoxicity.

The mean age of studied patients was $24.67 \pm 11.29$ years. This is in accordance with several studies reported that acute phosphide poisoning was common in young adults (El Naggar and El Mahdy., 2011; Soltaninejad et al., 2012 and Elghany et al., 2018).This was explained by exposure of this age group to unemployment and financial instability (Chandrakant et al., 2015; Dadpour et al., 2016). On the other hand, a study in India by Gupta et al. (2011) found that accidental ALP ingestion was common in children due to illiteracy and its easy availability in the Indian agricultural community.

Majority of acute phosphides intoxicated patients were females (63.3\%). Our result was supported by other studies, explained by higher liability of female to stress (Mahmoud et al., 2013; Sagah et al., 2015 and Hassanian-Moghaddam and Zamani, 2016). EtemadiAleagha et al. (2015) and Trakulsrichai et al. (2017) are against the current study as they reported that males were more exposed to acute phosphides toxicity than females and explained this by their involvement in various social activities exposing them to more stress.

Most of studied patients were students $(46.3 \%)$.This in agreement with Murari and Sharma (2014) and Sagah et al. (2015) who reported that acute phosphides poisoning was common in students in secondary school education due to admonishment from their teachers and failure or less percentages in exams. In contrast to our study, Anand et al. (2011) in India found that most of exposed patients were farmers or workers in the agriculture field.

In the current study, majority of patients were from Cairo (76.1\%). El Masry and Tawfik (2013) explained increased number of poisoned patients from Cairo by the proximity of PCC-ASUH to Cairo residents. In India, Chaudhary et al. (2013) found that most of their patients were from urban areas and explained this by globalization and migration of people to these areas leading to overcrowding and exposure to more social stress. This result differs from Mehrpour et al. (2012) study in Iran who found that most of his studied patients were from rural areas as these were agricultural communities and agricultural workers were the most vulnerable people.

Concerning type of phosphides, most of studied patients (92.7\%) were intoxicated with $\mathrm{ZnP}$ and only $7.4 \%$ were intoxicated with ALP. This study is in agreement with Wahdan and Elmadah (2016), who reported that ZnP
(52\%) was more common than ALP (48\%) among studied patients and also Badawi et al. (2018) study in Egypt found $\mathrm{ZnP}$ poisoning in $81.25 \%$ of studied patients while ALP poisoning represented only $18.75 \%$. Additionally, El Helaly and Tawfik (2015) stated that number of $\mathrm{ZnP}$ intoxicated patients who were admitted to the PCC-ASUH during 2013 and died were more than the number of ALP intoxicated patients. In Egypt, $\mathrm{ZnP}$ is mostly marketed for domestic use, while ALP is mainly used in silos in agricultural and storage uses and this may explain higher number of $\mathrm{ZnP}$ poisoning.

The majority of studied patients $(97.9 \%)$ were exposed to phosphides through ingestion and most of them attempted suicide (87.2\%).This study is similar to Trakulsrichai et al. (2017) who reported that majority of studied patients exposed to $\mathrm{ZnP}$ by suicidal ingestion (84.4\%). Gurjar et al. (2011) stated that suicide using ALP represented about one third of the suicidal causes worldwide. Regarding the amount of phosphides, $29.3 \%$ of studied patients were exposed to unknown amount of phosphides with the majority of $\mathrm{ZnP}$ poisoned patients were exposed to one sachet while ALP intoxicated patients were exposed to $0.25-1$ tablet. In line with our results, Sagah et al. (2015) study reported that $\mathrm{ZnP}$ intoxicated patients ingested from $0.25-2$ sachets and all of them were asymptomatic. Trakulsrichai et al. (2017) found that most of their studied patients were exposed to less than one sachet of $\mathrm{ZnP}$. The fatal dose of ALP is $150-500 \mathrm{mg}$ and the person who survives after ALP exposure has mostly used an expired form (Mehrpour et al. 2012; Mostafazadeh, 2012).These previous studies explained why most of $\mathrm{ZnP}$ studied patients in the current study were asymptomatic as they could have used either a small amount of $\mathrm{ZnP}$ which was less than the toxic dose or they might have mixed it with water that caused liberation of the toxic principle (phosphine gas) in air before consumption or they could have used the expired form. On the other hand, all ALP studied patients developed severe life threatening manifestations as each tablet of ALP could liberate about 1 gram of phosphine gas.

The delay time was statistically increased in group III (severe group). Shadnia et al. (2010) is in agreement with our study who found that the nonsurvivor group following acute ALP exposure had longer delay time. On the other hand, Teimoory et al. (2013); Marashi (2015) and Manouchehri et al. (2019) stated that symptoms following ALP exposure appeared early within 10-15 minutes of exposure while symptoms following $\mathrm{ZnP}$ exposure were milder and appeared later, as $\mathrm{ZnP}$ is more stable than ALP.

In the current study, $89.8 \%$ of $\mathrm{ZnP}$ intoxicated patients had normal blood pressure and $10.2 \%$ of them had hypotension. This result is in agreement with Sagah et al. (2015) who reported that almost all studied patients exposed to $\mathrm{ZnP}$ had normal blood pressure and Chugh et al. (2014) stated that only $20 \%$ of $\mathrm{ZnP}$ intoxicated 
patients developed hypotension. All ALP intoxicated patients in the current study had hypotension. This is in agreement with Shadnia et al. (2010) study who found that $94.87 \%$ of ALP studied patients developed hypotension and also Dadpour et al. (2016) found hypotension in $76-100 \%$ of ALP exposed patients. This could be attributed to direct myocardial damage, peripheral vasodilatation, left ventricular dysfunction or fluid loss through vomiting or diarrhea (Mathai and Bhanu., 2010; Gurjar et al., 2011 and Farahani et al., 2016).

More than half of studied patients had normal heart rate $(66.0 \%)$ while $28.7 \%$ of them had tachycardia and only $5.3 \%$ were bradycardic. Several studies are in agreement with our study as metal phosphides could cause normal pulse, tachycardia or less commonly bradycardia (Shadnia et al. 2010; El Naggar and El Mahdy., 2011 and Teimoory et al., 2013). Trakulsrichai et al. (2017) found that most of their studied patients had normal pulse, $14.2 \%$ had tachycardia and only $1.4 \%$ had bradycardia. In contrast to our study, Dadpour et al. (2016) in Iran reported tachycardia in most of ALP studied patients.

Most of studied patients (97.3\%) had normal respiratory rate while $2.7 \%$ of them were tachypnic. All patients who developed tachypnea in our study were exposed to ALP and had respiratory symptoms while those exposed to $\mathrm{ZnP}$ had normal respiratory rate. Anand et al. (2011); Singh et al. (2014) are in agreement with our study as they found that ALP toxicity caused tachypnea due to either pulmonary edema or adult respiratory distress syndrome (ARDS). Trakulsrichai et al. (2017) stated that most of their $\mathrm{ZnP}$ studied patients had normal respiratory rate and only $16 \%$ of them had tachypnea. In this study, the majority of studied patients $(92 \%)$ had normal temperature, $5.8 \%$ were hypothermic and $2.2 \%$ were feverish. In accordance with these results, Trakulsrichai et al. (2017) observed that most of studied patients had normal body temperature and only $5 \%$ had fever.

In the current study, most of $\mathrm{ZnP}$ intoxicated patients developed transient or no cardiovascular manifestations while all ALP intoxicated patients developed significant cardiotoxicity. Mathai and Bhanu (2010); Shadnia et al. (2010) are in accordance with our study as they reported that ALP toxicity causes chest pain and palpitation, in addition to shock which was a bad prognostic sign if became resistant to vasopressors. Bumbrah et al. (2012) reported that phosphine gas produced from hydrolysis of metal phosphides after inhalation causes chest tightness.

Outcome of the studied patients was determined as either recovery and discharge $(92 \%)$ or developing complications as $4.3 \%$ of patients developed respiratory failure and 5.9\% developed myocardial ischemia, and $2.7 \%$ died. Patients who developed complications or died in the current study were exposed to ALP while those who were exposed to $\mathrm{ZnP}$ had complete recovery and were discharged. Mathai and Bhanu (2010) and Sharma et al. (2014) reported that ALP toxicity was associated with resistant hypotension, metabolic acidosis, need for mechanical ventilation and high mortality. Death following ALP exposure in the current study occurred in the first 24 hours due to cardiotoxicity. Singh and Bhalla (2015) and Neki et al. (2017) are in accordance with our study as they found that death occurred in the first 24 hours following acute phosphides exposure was related to cardiotoxicity, shock or arrhythmia. Sagah et al. (2015) found that all studied patients of $\mathrm{ZnP}$ poisoning survived and were discharged from the hospital after achieving clinical improvement and explained this by ingestion of smaller amount of $\mathrm{ZnP}$ which was less than the fatal dose.

Regarding TAC, the severe group showed significant decrease in comparison with mild and moderate groups while there was non-significant difference between mild and moderate group. This result in agreement with Kariman et al. (2012) and Mehrpour et al. (2012) who found decrease in TAC in ALP studied patients. Several experimental studies reported that ALP could cause oxidative stress by production of oxygen free radicles, lipid peroxidation and impairment of mitochondrial electron transport chain resulting in decrease in TAC (Hsu et al., 2002 Nath et al., 2011; and Baghaei et al., 2016).These studies were supported with another study done by Halvaei et al. (2017) who reported that there was decrease in TAC after ALP exposure indicating oxidative stress which was improved after administration of vitamin $\mathrm{E}$ as an antioxidant.

Serum troponin I in the current study was significantly increased among patients of the severe group in comparison with patients of mild and moderate group while there was non-significant difference between mild and moderate group. Akhtar et al. (2015) found elevation of serum troponin I after accidental exposures to phosphine gas which indicate severe myocardial damage that could produce cardiovascular collapse and death. Kalawat et al. (2016) found that troponin I was elevated in $26 \%$ of studied patients after acute ALP toxicity and related this to myocardial damage by echocardiography not ECG changes. Mostafalou et al. (2013) and Hakimoğlu et al. (2015) are against our study as they reported that elevation of different cardiac enzymes such as CK-MB or troponin $\mathrm{T}$ ( $\mathrm{Tn} \mathrm{T}$ ) levels could approve cardiotoxicity and indicate mortality but their absence couldn't exclude cardiotoxicity after acute phosphides exposure.

Regarding ECG changes, sinus tachycardia was seen in $28.7 \%$ of studied patients, sinus bradycardia in $5.3 \%$, about $2 \%$ of patients had nodal rhythm, $1.14 \%$ had frequent PVCs and $0.56 \%$ had VT and VF was observed in $1.6 \%$ of studied patients. Soltaninejad et al. (2012) is in agreement with our study as 55\% of their studied patients had sinus rhythm and $45 \%$ of them had dysrhythmia. Also the authors found a direct relationship between ECG changes and mortality after ALP toxicity. Khater \& Sarhan (2015) is in agreement with our study as they found that 
about half of their $\mathrm{ZnP}$ intoxicated patients had normal ECG and 50\% had dysrhythmia. Trakulsrichai et al. (2017) observed sinus tachycardia as the most common type of arrhythmia after $\mathrm{ZnP}$ exposure among their studied patients. On the other hand, Siwach et al. (1998) and Dadpour et al. (2019) reported that the most common type of arrhythmia following acute ALP exposure was supraventricular tachycardia $(46.7 \%)$ followed by ventricular tachycardia (40\%), ventricular fibrillation $(23.3 \%)$ and $20 \%$ of patients developed either atrial flutter or atrial fibrillation and attributed this to toxic myocarditis. Bhalla (2017) and Manouchehri et al. (2019) found a direct relationship between fatal ALP toxicity and ECG changes.

As regard ST-T changes, elevated ST segment observed in $3.2 \%$ of studied patients, depressed ST segment in $2.7 \%$, inverted $\mathrm{T}$ wave in $10.6 \%$ and tall $\mathrm{T}$ wave $3.2 \%$. Mostafalou et al. (2013); Mehrpour et al.(2012) and Singh et al. (2014) stated that ST segment changes after ALP toxicity indicated myocardial infarction. Mohan et al. (2016) and Taghaddosinejad et al. (2016) explained ECG ischemic changes with metal phosphides by phosphine gas induced oxidative stress which results in production of oxygen free radicles and lipid peroxidation. Moreover, phosphine gas had a direct myocardial toxic effect causing change in membrane action potential which gives the ECG pattern of inferior wall myocardial ischemia.

Concerning ECG intervals, QTc interval was prolonged in all ALP intoxicated patients and $\mathrm{ZnP}$ intoxicated patients with moderate symptoms. In agreement with the current study, several studies reported prolonged QTc interval accompanied with either bradycardia or tachycardia following acute exposure to metal phosphides (Lionate et al., 2004; Jafari et al., 2015; Taghaddosinejad et al., 2016; Asghari et al., 2017 and Rahimi et al., 2018). Wide QRS complex was observed in $20.2 \%$ of the studied patients. Moghadamnia (2012) and Hashemi-Domeneh et al. (2016) are in accordance with our study as they reported incomplete or complete right bundle branch block with wide QRS complex after ALP exposure. Trakulsrichai et al. (2017) is against our study as they reported wide QRS complex in $1.2 \%$ only of studied patients with acute $\mathrm{ZnP}$ exposures. PR interval was prolonged in $\mathrm{ZnP}$ poisoning patients with moderate symptoms (all of them not exceeding $200 \mathrm{~ms}$ ). El Naggar and El Mahdy (2011) are in agreement with our study as they found prolonged PR interval among their $\mathrm{ZnP}$ intoxicated studied patients. Hashemi-Domeneh et al. (2016) is against our study as they reported AV block up to complete heart block after ALP exposure.

The current study revealed positive correlation between TAC and blood pressure. This is in agreement with Gurjar et al. (2011) study who found that ALP toxicity caused refractory hypotension through free radicle production with decrease in antioxidant enzymes as catalase and increase in markers of oxidative stress as superoxide dismutase. Chugh et al. (2011) found marked improvement of ALP intoxicated patients who had hypotension and increased level of malonyl-di-aldehyde (MDA) after administration of magnesium sulfate as antioxidant.

The present study showed negative correlation between TAC and pulse. Anand et al. (2011) and Mostafalou et al. (2013) found that ALP toxicity caused tachycardia, decrease in catalase enzyme (antioxidant enzyme) but increase in superoxide dismutase (indicator of oxidative stress) among studied patients. Shakeri and Mehrpour (2015) study is against our findings as they found that ALP exposure caused bradycardia with oxidative stress and lipid peroxidation in experimental rats.

The present study revealed that troponin I showed a negative correlation with blood pressure. El Hangouche et al. (2017) study is in accordance with our results that found a negative correlation between blood pressure and troponin I and stated that ALP toxicity induced myocardial injury and release of cardiac troponin. Akhtar et al. (2015) also reported hypotension and increase in troponin I level after ALP exposure.

Hickman et al. (2010) is in contrast to our study as he found that there was no relation between blood pressure and troponin I and stated that cardiac ischemia alone without cellular necrosis or effect on blood pressure caused release of troponin I in the circulation.

Troponin I showed a positive correlation with pulse in the current study. In line with our results, a similar observation was reported in the study of Akhtar et al. (2015), where phosphine gas after ALP exposure caused tachycardia with increase of troponin I level among studied patients. On the other hand, HassanianMoghaddam and Zamani. (2016) reported a case of ALP toxicity who developed bradycardia with normal troponin I level. Also Dadpour et al. (2016) reported that ALP exposure caused tachycardia but with normal level of troponin I among studied patients.

In the present study, TAC was lower in patients who developed cardiovascular manifestations and had ECG abnormalities. Hsu et al., (2002) and Gurjar et al. (2011) are in agreement with our study as they reported that ALP induced cardiotoxicity was caused by decrease level of glutathione and increase level of superoxide dismutase as glutathione is a protecting factor against oxidation that results in cellular injury including heart.

Bumbrah et al. (2012) noticed that ALP toxicity caused chest pain but decrease in catalase level and increase in superoxide dismutase. Gurjar et al. (2011) and Mehrpour et al. (2012) reported that ALP intoxicated patients with ECG changes had decrease in level of glutathione and increase in level of superoxide dismutase.

The value of troponin I was higher in studied patients who developed cardiovascular manifestations and ECG abnormalities. Akhtar et al. (2015) is in agreement with our study who observed increase of troponin I in accordance with cardiovascular symptoms after phosphine gas exposure among studied patients and found that troponin I was increased in parallel to ECG 
changes after phosphine gas exposure among studied patients.

The best cut off point of TAC in the current study was $\leq 0.07 \mathrm{mM} / \mathrm{L}$ and was associated with mortality with sensitivity of $100 \%$ and specificity of $63.54 \%$. Kariman et al. (2012) reported that ALP toxicity induced an oxidative stress with decreased TAC $(1.91 \pm 0.18$ $\mathrm{mmol} / \mathrm{ml}$ ) and stated that phosphine induced oxidative damage was associated with mortality but no cut off point was determined in their study. On the other hand, Halvaei et al. (2017) found no difference in the value of TAC between control and treatment group with antioxidant after ALP exposure.

\section{Conclusion}

The current study concluded that $\mathrm{ZnP}$ is more commonly used than ALP to commit suicide among young adult females in Egypt. ALP poisoning usually results in mortality rather than morbidity as mortality occurs in up to $100 \%$ of patients with acute poisoning. Metal phosphides induced cardiotoxicity could be attributed to oxidative stress as TAC decreased in studied patients who developed cardiovascular manifestations, had ECG changes and increased troponin I level. Initial TAC and troponin I levels in patients with acute metal phosphides poisoning could be useful in predicting development of oxidative damage and cardiotoxicity that may reduce mortalities and improve outcome among these poisoned patients.

\section{Recommendations}

The present study recommended the use of TAC and troponin I as useful markers for prediction of cardiotoxicity and mortality in patients with acute metal phosphides poisoning. Awareness should be raised among people who are handling phosphides about their lethal effects and keeping them away from the reach of children and other vulnerable family members. The government should also restrict sale and distribution of ALP as a rodenticide to prevent further deaths as a result from self-poisoning and misuse. Further researches are needed to plan the possible role for exogenous antioxidant agents for treatment of metal phosphides poisoning.

\section{References}

Akhtar, S., Rehman, A., Bano, S., \& Haque, A. (2015): Accidental phosphine gas poisoning with fatal myocardial dysfunction in two families. Journal of the College of Physicians and Surgeons Pakistan, 25 (5): 378-379.

Allard, J.P., Aghdassi, E., Chau, J., Salit, I., \&Walmsley, S. (1998): Oxidative stress and plasma antioxidant micronutrients in humans with HIV infection. The American journal of clinical nutrition; 67: 143-147.

Anand, R., Binukumar, B.K., \& Gill, K. D. (2011): Aluminum phosphide poisoning: an unsolved riddle. Journal of applied toxicology; 31(6): 499-505.

Asghari, M. H., Abdollahi, M., de Oliveira, M. R., \& Nabavi, S. M. (2017): A review of the protective role of melatonin during phosphine-induced cardiotoxicity: focus on mitochondrial dysfunction, oxidative stress and apoptosis. Journal of Pharmacy and Pharmacology; 69(3): 236-243.

Badawi, S. M., Alseidy, A. M., Alfeki, A. K., Mansour, M., \& El-Hamid, A. A. (2018): Metal phosphide poisoning in Menoufia University Hospitals. Menoufia Medical Journal,31(3); 816.

Baghaei , A., Solgi, R., Jafari, A., Abdolghaffari, A. H., Golaghaei, A., Asghari, M.H., Baeeri, M., Ostad, S.N., Sharifzadeh, M. \& Abdollahi, M. (2016): Molecular and biochemical evidence on the protection of cardiomyocytes from phosphine-induced oxidative stress, mitochondrial dysfunction and apoptosis by acetyl-1-carnitine. Environmental toxicology and pharmacology; 42: 30-37.

Bhalla, A. (2017): Chapter 94 " Phosphate and Phosphine". In: Critical Care Toxicology: Diagnosis and Management of the Critically Poisoned Patient (second edition). Brent, J., Burkhart, K., Dargan, P., Hatten, B., Mégarbane, B., Palmer, R., White, J. (Eds.). Springer International publishing .P. 1875-1885.

Bumbrah, G. S., Krishan, K., Kanchan, T., Sharma, M., \& Sodhi, G. S. (2012): Phosphide poisoning: a review of literature. Forensic science international; 214(1-3): 1-6.

Chandrakant, V. A., \& RG, H. K. (2015): A Pattern of Acute Poisoning in Dharwad-India. MedicoLegal Update; 15(1): 9-12.

Chaudhary, S., Momin, S.G., Vora, D. H., Modi, P., Chauhan, V., \& Chotaliya, D. (2013): An epidemiological study of fatal aluminium phosphide poisoning at Rajkot. IOSR Journal of pharmacy, 3(1); 17-23.

Chugh, S. N., Pal, R., Singh, V., \& Seth, S. (2011): Serial blood phosphine levels in acute aluminum phosphide poisoning. The Journal of the Association of Physicians of India; 44(3): 184185.

Chugh, S. N., Aggarwal, H. K., \& Mahajan, S. K. (2014): Zinc phosphide intoxication symptoms: analysis of 20 cases.International journal of clinical pharmacology and therapeutics, 36(7); 406-407.

Dadpour, B., Mokhtarpour, M., Abdollahi, M., \& Afshari, R. (2016): An outbreak of aluminium phosphide poisoning in Mashhad, Iran. Arhiv za higijenu rada i toksikologiju, 67(1); 65-66.

Dadpour, B., Milani, N., Mehrpour, O., \& Najari, F. (2019): Acute myocardial injury and electrocardiogram changes in a case of aluminum phosphide poisoning. International 
journal of medical toxicology and forensic medicine; 9(2 (spring): 91-96.

Doğan, E., Güzel, A., Çiftçi, T., Aycan, İ., Çelik, F., Çetin, B., \& Kavak, G. Ö. (2014): Zinc phosphide poisoning. Case reports in critical care, vol. 2014, Article ID 589712, 3 pages, 2014. https://doi.org/10.1155/2014/589712.

Dunn, J. A., Schroeppel, T. J., Metzler, M., Cribari, C., Corey, K., \& Boyd, D. R. (2018): History and significance of the trauma resuscitation flow sheet. Trauma Surgery \& Acute Care Open; 3(1): e000145.

Elabbassi, W., Chowdhury, M. A., \& Fachtartz, A. A. N. (2014): Severe reversible myocardial injury associated with aluminum phosphide toxicity: a case report and review of literature. Journal of the Saudi heart association; 26(4): 216-221.

El Hangouche, A. J., Fennich, H., Alaika, O., Dakka, T., Raissouni, Z., Oukerraj, L., Doghmi, N. \& Cherti, M. (2017): Reversible myocardial injury and intraventricular thrombus associated with aluminium phosphide poisoning. Case reports in cardiology, vol. 2017, Article ID 6287015, 6 pages, 2017. https://doi.org/10.1155/2017/6287015.

El Helaly, H. \& Tawfik, H. (2019): Toxicological profile of acutely poisoned cases admitted to poison control center, Ain-Shams University Hospitals during Year 2013. Ain Shams Journal of Forensic Medicine and Clinical Toxicology, 24: 154-163.

Elghany, S.A.A., Heshmat, M.M., Oreby, M., \& Elsarnagawy, G.N. (2018): Evaluation of various scoring systems in prediction of acute aluminum phosphide (ALP) poisoning outcome. Ain Shams Journal of Forensic Medicine and Clinical Toxicology; 30, 117-127.

El Masry, M.K. \& Tawfik, H.M. (2013): 2011 Annual report of the poison control centre of Ain Shams University Hospital, Cairo, Egypt. Ain Shams J Forensic Med Clin Toxicol; 20(1), 10-17.

El Naggar, A.R.M., \& El Mahdy, N.M. (2011): Zinc phosphide toxicity with a trial of tranexamic acid in its management. Journal of Advanced Research; 2(2): 149-156.

Etemadi-Aleagha, A., Akhgari, M., \& Iravani, F. S. (2015): Aluminum phosphide poisoning-related deaths in Tehran, Iran, 2006 to 2013. Medicine; 94(38).

Farahani, M.V., Soroosh, D., \& Marashi, S.M. (2016): Thoughts on the current management of acute aluminum phosphide toxicity and proposals for therapy: An evidence-based review. Indian journal of critical care medicine: peer-reviewed, official publication of Indian Society of Critical Care Medicine; 20(12): 724.

Goharbari, M. H., Taghaddosinejad, F., Arefi, M., Sharifzadeh, M., Mojtahedzadeh, M., Nikfar, S., Baeeri, M., Rahimifard, M. \& Abdollahi, M.
(2018): Therapeutic effects of oral liothyronine on aluminum phosphide poisoning as an adjuvant therapy: A clinical trial. Human \& experimental toxicology; 37(2): 107-117.

Gupta, V., Natarajan, C., Kumar, K., \& Prasanna, R. (2011): Identification and characterization of endoglucanases for fungicidal activity in anabaena laxa (Cyanobacteria).Journal of applied phycology; 23(1): 73-81.

Gurjar, M., Baronia, A. K., Azim, A., \& Sharma, K. (2011): Managing aluminum phosphide poisonings. Journal of emergencies, trauma and shock; 4(3): 378.

Hakimoğlu, S., Dikey, İ., Sarı, A., Kekeç, L., Tuzcu, K., \& Karcioğlu, M. (2015): Successful management of aluminium phosphide poisoning resulting in cardiac arrest. Turkish journal of anaesthesiology and reanimation, 43(4); 288.

Halvaei, Z., Tehrani, H., Soltaninejad, K., Abdollahi, M., \& Shadnia, S. (2017): Vitamin E as a novel therapy in the treatment of acute aluminum phosphide poisoning. Turkish journal of medical sciences, 47(3); 795-800.

Hashemi-Domeneh, B., Zamani, N., HassanianMoghaddam, H., Rahimi, M., Shadnia, S., Erfantalab, P., \& Ostadi, A. (2016): A review of aluminium phosphide poisoning and a flowchart to treat it. Archives of industrial hygiene and toxicology; 67(3) 183-193.

Hassanian-Moghaddam, H. \& Zamani, N. (2016): Therapeutic role of hyperinsulinemia/ euglycemia in aluminum phosphide poisoning. Medicine; 95(31).

Hickman, P.E., Potter, J.M., Aroney, C., Koerbin, G., Southcott, E., Wu, A.H., \& Roberts, M.S. (2010): Cardiac troponin may be released by ischemia alone, without necrosis. Clinica chimica acta, 411(5-6); 318-323.

Hsu, C.H., Chi, B.C., Liu, M.Y., Li, J.H., Chen, C. J., \& Chen, R.Y. (2002): Phosphine-induced oxidative damage in rats: role of glutathione. Toxicology; 179(1-2): 1-8.

Jafari, A., Baghaei, A., Solgi, R., Baeeri, M., Chamanara, M., Hassani, S., Gholami, M., Ostad, S.N. \& Abdollahi, M. (2015): An electrocardiographic, molecular and biochemical approach to explore the cardioprotective effect of vasopressin and milrinone against phosphide toxicity in rats. Food and Chemical Toxicology: 80: 182-192.

Jain, Piyush. (2018): Zinc phosphide poisoning. Indian Journal of Medical Specialities; 9(3), 171-173.

Kalawat, S., Thakur, V., Thakur, A., \& Punjabi, N.D. (2016): Cardiovascular profile of aluminium phosphide poisoning and its clinical significance. Int Adv Med, 3; 859-64.

Kariman, H., Heydari, K., Fakhri, M., Shahrami, A., Dolatabadi, A. A., Mohammadi, H. A., \& Gharibi, M. (2012): Aluminium phosphide 
poisoning and oxidative stress. Journal of Medical Toxicology; 8(3): 281-284.

Khater, A.S., and Sarhan, N.M. (2015): Cardiotoxicity in Acute Zinc Phosphide Intoxicated Patients (A Prospective Study). Ain Shams Journal of Forensic Medicine and Clinical Toxicology Jan 2015, 24: 44-52

Kumar, A., Singh, C.V., Dayal, S., Gupta, V.K., Kumar, S., \& Verm, A. (2013): Case report: acute severe suicidal poisoning by celphos powder a rare case report from rural India'. J Indian Acad Forensic Med. July-September; 35(3): 09710973.

Lionte, C.; Sorodoc, L. \& Laba, V. (2004): Zinc phosphide poisoning - diagnosis, complications, management. Terapeutica, Farmacologie si Toxicologie Clinica; 8(4):87-91, ISSN 1583-0012.

Manouchehri, A., Ahangar, R.M., Bigvand, P., Nakhaee, S., \& Mehrpour, O. (2019): Successful treatment of heart failure due to simultaneous poisoning with aluminum phosphide and zinc phosphide: a case report. Iranian Red Crescent Medical Journal; 21(3).

Marashi, S.M. (2015): What really happens after zinc phosphide ingestion? A debate against the current proposed mechanism of phosphine liberation in zinc phosphide poisoning. European review for medical and pharmacological sciences; 19(22): 4210-4211.

Mathai, A. \& Bhanu, M.S. (2010): Acute aluminium phosphide poisoning: can we predict mortality? Indian journal of anaesthesia, 54(4); 302.

Mehrpour, O., Alfred, S., Shadnia, S., Keyler, D. E., Soltaninejad, K., Chalaki, N., \& Sedaghat, M. (2012): Hyperglycemia in acute aluminum phosphide poisoning as a potential prognostic factor. Human \& experimental toxicology; 27(7): 591-595.

Moghadamnia, A.A. (2012): An update on toxicology of aluminum phosphide. DARU journal of Pharmaceutical Sciences; 20(1): 25.

Mohan, B., Singh, B., Gupta, V., Ralhan, S., Gupta, D., Puri, S., Goyal, A., Aslam, N., Tandon, R. \& Wander, G. S. (2016): Outcome of patients supported by extracorporeal membrane oxygenation for aluminum phosphide poisoning: An observational study.Indian Heart Journal; 68(3): 295-301.

Mostafalou, S., Karami-Mohajeri, S., \& Abdollahi, M. (2013): Environmental and population studies concerning exposure to pesticides in Iran: a comprehensive review. Iranian Red Crescent Medical Journal; 15(12).

Mostafazadeh, B. (2012): Aluminum phosphide poisoning. In: Toxicity and drug testing. Acree, B. (ed). InTech, Rijeka, pp 345-360.

Murari, A. \& Sharma, G. K. (2014): A comparative study of poisoning cases autopsied in LHMC*, New
Delhi and JIPMER** Pondicherry. Journal of Forensic medicine and Toxicology, 19(1); 18-20.

Nath, N. S., Bhattacharya, I., Tuck, A.G., Schlipalius, D. I., \& Ebert, P.R. (2011): Mechanisms of phosphine toxicity. Journal of toxicology, vol. 2011, Article ID 494168, 9 pages, 2011. https://doi.org/10.1155/2011/494168.

Neki, N. S., Shergill, G. S., Singh, A., Kaur, A., Nizami, S., Singh, T., \& Pannu, J. S. (2017): Recent advances in management of aluminium phosphide poisoning. Int $\mathbf{J}$ Curr Res Med Sci Updat Artic; 3(3), 73-76.

Persson, H. E., Sjöberg, G. K., Haines, J. A., \& de Garbino, J. P. (1998): Poisoning severity score. Grading of acute poisoning. Journal of Toxicology: Clinical Toxicology; 36(3): 205-2.

Rahimi, N., Abdolghaffari, A.H., Partoazar, A., Javadian, N., Dehpour, T., Mani, A.R., \& Dehpour, A.R. (2018): Fresh red blood cells transfusion protects against aluminum phosphide-induced metabolic acidosis and mortality in rats. PloS one;13(3), e0193991.

Rees, C., Neill, S., Crawford, D., Bolland, R., Sefton, G., \& Fortune, P.M. (2017): Standards for Assessing,Measuring and Monitoring ,Vital Signs in Infants, Children and Young People. Royal College of Nursing; 7(Appendix1):19.

Sagah, G.A., Oreby, M., El-Gharbawy, R.M. and Hafez, A.S.A. (2015): Evaluation of potential oxidative stress in Egyptian patients with acute zinc phosphide poisoning and the role of vitamin $\mathrm{c}$. Int J Health Sci (Qassim); 9(4) :375-385.

Shadnia, S., Mehrpour, O., \& Soltaninejad, K. (2010): A simplified acute physiology score in the prediction of acute aluminum phosphide poisoning outcome. Indian journal of medical sciences, 64(12); 532.

Shakeri, S. and Mehrpour, O. (2015): Aluminum phosphide poisoning in animals. International Journal of Medical Toxicology and Forensic Medicine; 5(2): 81-97.

Sharma, D., Meena, C., Mittal, L. C., Yadav, G., \& Meena, S. (2014): Aluminium phosphide poisoning. Indian Medical Gazette; 9: 333-9.

Singh, S., Dilawari, J.B., Vashisht, R., Malhotra, H.S., Sharma, B.K. (2014): Aluminum phosphide ingestion. British Medical Journal; 290:11101111.

Singh, S., \& Bhalla, A. (2015): Aluminum phosphide poisoning. Journal of Mahatma Gandhi Institute of Medical Sciences; 20(1): 15.

Sinha, N. (2018): Aluminium phosphide poisoning. Indian Journal of Medical Specialities ; 9(3), $167-170$

Siwach, S.B., Singh, H., Jagdish, Katyal, V.K. \& Bhardwaj, G. (1998): Cardiac arrhythmias in aluminum phosphide poisoning studied by on 
continuous holter and cardioscopic monitoring. J Assoc Physicians India: 46; 598-601.

Soltaninejad, K., Beyranvand, M. R., Momenzadeh, S. A., \& Shadnia, S. (2012): Electrocardiographic findings and cardiac manifestations in acute aluminum phosphide poisoning. Journal of forensic and legal medicine; 19(5): 291-293.

Taghaddosinejad, F., Farzaneh, E., Ghazanfari-Nasrabad, M., Eizadi-Mood, N., Hajihosseini, M., \& Mehrpour, O. (2016): The effect of N-acetyl cysteine (NAC) on aluminum phosphide poisoning inducing cardiovascular toxicity: a case-control study. SpringerPlus; 5(1): 1948.

Teimoory, M., Aghabiglooie, A., \& Shadinia, S. (2013): Determining clinical symptoms of getting poisoned by aluminium phosphide in comparison with getting poisoned by zinc phosphide, in relation with patients of loqman hospital. J Basic Appl Scient Res;3(8): 410-17.

Trakulsrichai, S., Kosanyawat, N., Atiksawedparit, P., Sriapha, C., Tongpoo, A., Udomsubpayakul, U., Rittilert, P. \& Wananukul, W. (2017): Clinical characteristics of zinc phosphide poisoning in
Thailand. Therapeutics and clinical risk management; 2017 (13): 335-340.

Wahdan, A.A. \& Elmadah, E.I. (2016): Methemoglobinemia and intravascular hemolysis; unusual presentations of metal phosphides poisoning.Ain Shams Journal of Forensic Medicine and Clinical Toxicology, 26; 129-139.

Xue, Y., Daniels, L. B., Maisel, A. S., \& Iqbal, N. (2014): Chapter "Cardiac Biomarkers". In Reference Module in Biomedical Sciences. Caplan, M. \& Bradshow, R. (Eds.). Elsevier, DOI: 10.1016/B978-0-12-801238-3.00022-2.

Yogendranathan, N., Herath, H.M.M.T.B., Sivasundaram, T., Constantine, R., \& Kulatunga, A. (2017): A case report of zinc phosphide poisoning: complicated by acute renal failure and tubulo interstitial nephritis. BMC Pharmacology and Toxicology; 18(1): 37 .

\section{تقييم دور قرة مضاد التأكسد الكلية وثزويونين آى كمتنبؤات ممكنة للسمية القلبية التى تسببها الفوسفيدات

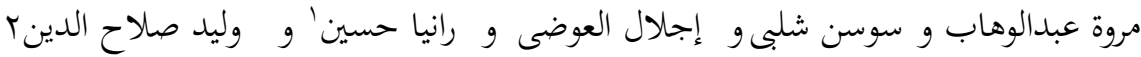

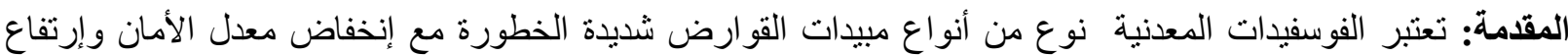

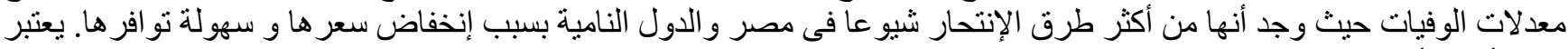
القلب أحد الأعضاء الهامة المستهدفة نتيجة السمية الحادة للفوسفيدات المعدنية مما يتسبب في التهاب عضلة القلب وتلفها.

الهُف من الاراسة:هدفت هذه الدر اسة إلى تقييم مدى إفادة قدرة مضاد التأكسد الكلية وتروبونين آى كمؤشر ات حيوية تنبؤية

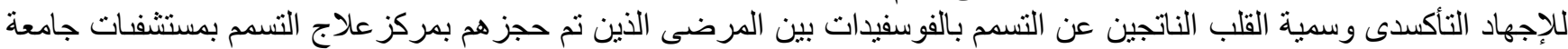

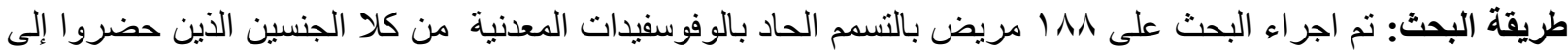

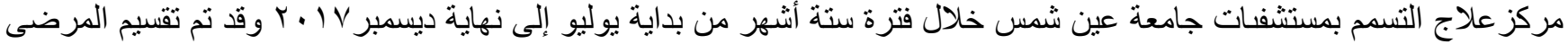
وفقا لدرجة شدة التسمح إلى ثلاثة مجمو عات: بسيطة ومنوسطة و شديدة وقد تم جمع البيانات السكانية و السمية و كذللك الإكلينيكية لكل

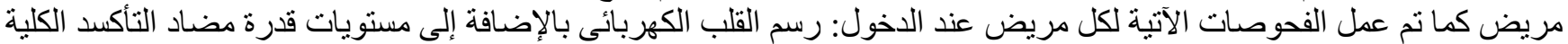
وتروبونين آى فى الدم وكذلك تم تسجيل نتيجة المرضى (تحسن , مضاعفات التيل , وفاة).

نتائج البحث: كانت نتائج الدر اسة كما يلى: بالنسبة للقيمة المتوسطة لقدرة مضاد التأكسد الكلية كانت أقل ونسبة تروبونين ائ

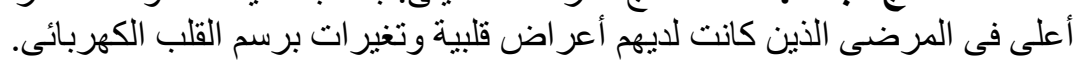
الخلاصة: خلصت هذه الدراسة إلى أن مستويات قدرة مضاد التأكسد الكلية وتروبونين آى من المككن أن تكون مفيدة في التنبؤ بحدوث الضرر التأكسدى ,تسمم القلب و الوفاة الناتجة عن التسمم الحاد بالفوسفيدات المعدنية.

التوصيات:توصى هذه الدر اسة بإستخدام قدرة مضاد التأكسد الكلية وتروبونين آى كدلالات مفيدة للتنبؤ بحدوث تسمم القلب و الوفاة فى مرضى التسمم الحاد بالفوسفيدات المعدنية. 